\title{
1998 Call for Papers Guidelines for Participation
}

When submitting panel and individual paper proposals, keep in mind the five participation rules developed by the APSA Council.

\section{Participation Limitation}

In the Fall of 1987, in order to provide opportunities in the Annual Meeting by the greatest number of people, the APSA Council limited participation in the Program. As a result, presenters are limited to TWO APPEARANCES on sessions organized by the APSA Program Committee, Organized Sections, and Related Group panels.

An appearance on the Annual Meeting Program takes the form of chair, paper or roundtable presenter, or discussant.

2. Preregistration

The APSA Council requires all program participants to preregister by March 13, 1998. Participants who do not preregister by March 13 will not be listed in the Final Program.

\section{Exempt Participants}

Prospective participants may request of a division chair or program organizer an exemption from the preregistration requirement if they are: A) not a political scientist; B) appearing on only one panel; and C) not an exempt participant in 1997. An exempt participant receives a badge for admission to all Annual Meeting activities but will not receive an Annual Meeting Program or the reduced hotel rate.

\section{Paper Delivery}

As paper presenters you have two important obligations: $A$ ) to ensure that the members of your panel, especially discussants, receive your paper in time to read it carefully prior to the meeting; and B) to submit 50 copies of the paper to the panel paper room at the hotel by the first day of the Annual Meeting.

\section{Panel Schedule}

Panels are scheduled in fourteen (14) time slots beginning at 8:45 a.m. on Thursday and concluding at 12:30 p.m. on Sunday. Participants are expected to be available for any of the fourteen time slots. If your schedule is limited by a teaching or travel constraint, inform the division chair or program organizer upon your acceptance as a participant, or by March 13, 1998. 